\title{
General Psychiatry A case of clozapine-induced skin picking behaviour
}

To cite: Reddy B, Das S, Guruprasad S. A case of clozapine-induced skin picking behaviour. General Psychiatry 2018;31:e000012. doi:10.1136/ gpsych-2018-000012

Received 01 November 2018 Revised 02 November 2018 Accepted 06 July 2018
Check for updates

(C) Author(s) (or their employer(s)) 2018. Re-use permitted under CC BY-NC. No commercial re-use. See rights and permissions. Published by BMJ.

${ }^{1}$ Department of Psychiatry, National Institute of Mental Health and Neurosciences (NIMHANS), Bengaluru,

Karnataka, India

${ }^{2}$ G.K.Reddy Hospital, Kadapa, Andhra Pradesh, India

Correspondence to Balaswamy Reddy; gbalambbs7819@gmail.com

Balaswamy Reddy, ${ }^{1}$ Soumitra Das, ${ }^{1}$ Srinivas Guruprasad ${ }^{2}$

\section{SUMMARY}

There is some evidence consistently linking the occurrence of de novo obsessive-compulsive disorder (OCD) with clozapine. This skin-picking disorder is also known as impulsive-compulsive disorder-unspecified which with an increasing convergence with OCD has been placed in the current Diagnostic and statistical manual of mental disorders-fifth edition by American Psychiatric Association (DSM-5), in the category of the obsessive-compulsive and related disorders. To the best of our knowledge, there is no literature relating antipsychotics like clozapine with the occurrence of skin-picking behaviour. In this article, we present a case in whom skin-picking behaviour emerged during the upward dose titration of clozapine and was successfully treated with escitalopram.

\section{INTRODUCTION}

There is some evidence consistently linking the occurrence of de novo obsessive-compulsive disorder (OCD) with second-generation antipsychotics (SGAs). Among the SGAs particularly, clozapine is most often found to be associated with high prevalence rates of obsessive-compulsive (OC) symptoms (often up to 28.4\%) and associated with higher doses, high plasma concentrations and the first 3-month period after the initiation. ${ }^{1-3}$

Skin-picking disorder is also known as impulsive-compulsive disorder-unspecified in the previous editions of DSM. It is phenomenologically similar to the OCD spectrum of illnesses, hence it has been placed in the current DSM-5 in the new diagnostic category of OC and related disorders. Compulsive skin-picking behaviour is characterised by excessive scratching or picking of normal skin or skin with minor surface irregularities on motor impulses. 4

\section{CASE HISTORY}

A 26-year-old man, diagnosed with mild intellectual developmental disorder $(\mathrm{IQ}=61)$ and treatment-resistant schizophrenia, was admitted for a trial of clozapine. He was started on clozapine from $25 \mathrm{mg}$ and hiked up to $300 \mathrm{mg}$ / day over a period of 2 months with partial response. Subsequently, the dose was increased to $350 \mathrm{mg}$ / day for 2 weeks followed by $400 \mathrm{mg}$ / day to continue as the final target dose. Clozapine was prescribed as a nocturnal dose from the beginning (of the clozapine trial). From a dose of $350 \mathrm{mg} /$ day onwards, the patient started developing an ulcer over the upper lip extending to his cheeks. Ward observation suggested the ulcer as a self-inflicted one. The patient reported that he used to have a repetitive urge to scratch the skin which could not be explained with psychopathologies such as psychotic experiences, OC symptoms or local dermatological causes. Furthermore, there was worsening in the severity of ulcer along with an escalation of the dose of clozapine $(350 \mathrm{mg}$ / day to 400 $\mathrm{mg} /$ day). Clozapine was continued despite worsening of the scratching behaviour because of the proportionate response in the psychotic symptoms on Positive and Negative Syndrome Scale (PANSS) scores. His PANSS total scores were as follows: at baseline $=112$, at 4 weeks $=108$, at 8 weeks $=94$, at 10 weeks $=80$, at 12 weeks $=74$. Finally, it was regarded as a clozapine-induced skin picking behaviour which did not have any further cognitive explanations like OCD or psychotic phenomenon. In view of the good response to clozapine, he was tried on escitalopram $10 \mathrm{mg} /$ day rather than reducing the primary drug. Over a period of 2 weeks, there was a significant reduction in the skin-picking behaviour. In a later follow-up (ie, at the 8th month), he had stopped escitalopram for 20 days when this behaviour recurred again. Hence, the patient was restarted on escitalopram $10 \mathrm{mg} /$ day which again led to significant improvement after 2 months. On the Naranjo Adverse Drug Reaction Probability Scale (APS), ${ }^{5}$ we calculated a score of $7 / 13$ for this occurrence which suggested a probable association.

\section{DISCUSSION}

There is a paucity of neurobiological research on skin-picking disorder, other than a few reports suggesting stimulants that act on 
dopamine and serotonin-like methamphetamine can induce skin-picking behaviour in preclinical studies. ${ }^{6}$ Recent research findings suggest an increasing convergence between 'compulsive-impulsive' disorders like skinpicking disorder and the OCD spectrum of illnesses. ${ }^{4}$

Patients with schizophrenia treated with clozapine reported having a higher prevalence of hypochondriasis and OC spectrum of illnesses, and a part of this was attributed to the de novo onset or an exacerbation of existing symptoms. ${ }^{7}$ Worsening of existing symptoms occurs in a subgroup of patients with hypochondriasis/ OCD, who had certain polymorphisms of SLC1A1/ GRIN2B genes, whereas the de novo occurrence of OC symptoms was attributed to the role of clozapine's strong antagonistic activities at 5-HT2A, 5-HT1C, 5-HT2C and glutamatergic receptors. The hypothesis is that this strongest antagonism can lead to the supersensitivity of 5-HT2A receptors which in turn can cause OC-like symptoms. This concurs with the existing evidence of up-regulated 5-HT2A receptors in the caudate nucleus of untreated OCD patients in comparison with the controls, and also a reversal of this upregulation post-treatment suggests that it may be a compensatory response to a serotonin deficiency state, in particular neural circuitry. ${ }^{8}$ Whereas the indirect evidence for this theory of high-affinity serotonin antagonism-induced complex alterations in above receptors come from the observation that some patients with OCD can improve with the addition of aripiprazole (which has a partial agonistic properties at 5-HT 1A and antagonist at 5-HT 2A), and drugs with exclusive dopamine/D2 activity like amisulpiride/haloperidol have been associated with the relative absence of OC-like symptoms. ${ }^{19}$

Early onset of OC symptoms in patients treated with clozapine mostly occur within 4 to 12 weeks after the initiation of treatment, with higher doses and plasma concentrations. Treatment options for this include dose-reduction strategy, aripiprazole, selective serotonin reuptake inhibitors, anti-epileptic medications like lamotrigine. $^{110}$

In our case, the skin-picking behaviour had occurred with clozapine at a dose of $350 \mathrm{mg} /$ day. This was neither explained by the patient's psychotic experiences nor by any de novo OC symptoms or local dermatological causes. Therefore, we had considered skin-picking behaviour in him as an exclusion of other diagnoses. We managed it with the addition of escitalopram, as a dose-reduction strategy was not found to be feasible. With $10 \mathrm{mg}$ of escitalopram, symptoms improved gradually within 2 weeks and also, in this case, it was found to recur and respond even after the subsequent default and restart of escitalopram, respectively, at a later follow-up date.

Acknowledgements We would like to thank the patient and his parents.

Contributors SD provided the case report and did editing on the manuscript. SG did the literature search and finalised the references. BSR prepared the manuscript draft in all stages including the final draft, reviewed and approved by coauthors.

Funding The authors have not declared a specific grant for this research from any funding agency in the public, commercial or not-for-profit sectors.

Patient consent Obtained.

Provenance and peer review Not commissioned; externally peer reviewed.

Open access This is an open access article distributed in accordance with the Creative Commons Attribution Non Commercial (CC BY-NC 4.0) license, which permits others to distribute, remix, adapt, build upon this work non-commercially, and license their derivative works on different terms, provided the original work is properly cited and the use is non-commercial. See: http://creativecommons.org/ licenses/by-nc/4.0

\section{REFERENCES}

1 Grover S, Hazari N, Chakrabarti S, et al. Relationship of obsessive compulsive symptoms/disorder with clozapine: a retrospective study from a multispeciality tertiary care centre. Asian J Psychiatr 2015;15:56-61.

2 Lin SK, Su SF, Pan CH. Higher plasma drug concentration in clozapine-treated schizophrenic patients with side effects of obsessive/compulsive symptoms. Ther Drug Monit 2006;28:303-7.

3 Mahendran R, Liew E, Subramaniam M. De novo emergence of obsessive-compulsive symptoms with atypical antipsychotics in asian patients with schizophrenia or schizoaffective disorder: a retrospective, cross-sectional study. J Clin Psychiatry 2007;68:542-5.

4 Bienvenu OJ, Samuels JF, Riddle MA, et al. The relationship of obsessive-compulsive disorder to possible spectrum disorders: results from a family study. Biol Psychiatry 2000;48:287-93.

5 Naranjo CA, Busto U, Sellers EM, et al. A method for estimating the probability of adverse drug reactions. Clin Pharmacol Ther 1981;30:239-45.

6 Mori T, Ito S, Kita T, et al. Effects of dopamine- and serotonin-related compounds on methamphetamine-induced self-injurious behavior in mice. J Pharmacol Sci 2004;96:459-64.

7 Grassi G, Poli L, Cantisani A, et al. Hypochondriasis and obsessivecompulsive disorder in schizophrenic patients treated with clozapine vs other atypical antipsychotics. CNS Spectr 2014;19:340-6.

8 Adams KH, Hansen ES, Pinborg LH, et al. Patients with obsessivecompulsive disorder have increased 5-HT2A receptor binding in the caudate nuclei. Int J Neuropsychopharmacol 2005;8:391-401.

9 Schirmbeck F, Esslinger C, Rausch F, et al. Antiserotonergic antipsychotics are associated with obsessive-compulsive symptoms in schizophrenia. Psychol Med 2011;41:2361-73.

10 Selles RR, McGuire JF, Small BJ, et al. A systematic review and meta-analysis of psychiatric treatments for excoriation (skin-picking) disorder. Gen Hosp Psychiatry 2016;41:29-37.

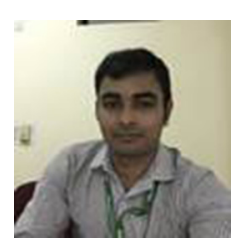

Balaswamy Reddy obtained the MBBS degree from the Rajiv Gandhi Institute of Medical Sciences (RIMS), Kadapa, Andhra Pradesh, India, in 2014. He started the masters program in psychiatry (MD psychiatry) at the National Institute of Mental health and Neurosciences (NIMHANS), Bengaluru, India, in 2015. He is currently working as a junior resident in MD psychiatry at the National Institute of Mental health and Neurosciences (NIMHANS). His research interests include psychosomatic disorders, psychopharmacology, and neurobiology of psychiatric disorders. He is also working on a systematic review/meta-analysis on schizophrenia research as our next project. 